\title{
A Formação Serra Alta, Permiano, no centro-leste do Estado de São Paulo, Bacia do Paraná, Brasil
}

\author{
The Serra Alta Formation, Permian, in the central-eastern \\ portion of São Paulo State, Paraná Basin, Brazil
}

\author{
Lucas Veríssimo Warren ${ }^{1 *}$, Mario Luis Assine ${ }^{1}$, Marcello Guimarães Simões ${ }^{2}$, \\ Claudio Riccomini ${ }^{3}$, Luís Eduardo Anelli ${ }^{3}$
}

\begin{abstract}
RESUMO: A individualização e o mapeamento da Formação Serra Alta no Estado de Sáo Paulo sempre foi motivo de controvérsia na comunidade geológica. Apesar de apresentar extensão comparável à Formação Irati em subsuperfície, a unidade ainda carece de estudos mais acurados acerca de seu posicionamento estratigráfico, conteúdo fossilífero, sistema deposicional e idade. Na região centro-leste do Estado de São Paulo, a Formaçáo Serra Alta sucede estratigraficamente a Formação Irati, sendo constituída por depósitos pelíticos cinza escuros. A unidade é mapeada desde o limite sul do estado até o Domo de Gibóia, no Município de Rio das Pedras. Neste local, as formaçóes Serra Alta e Teresina são substituídas pelos depósitos pelíticos da Formação Corumbataí, que se estende para norte, além do limite do Estado de São Paulo, e pode ser considerada unidade correlata a estas. Neste estudo, são apresentadas seçóes colunares e caracterizados os contatos da Formaçâo Serra Alta com as formaçôes permianas verticalmente contíguas. É apresentada também detalhada análise de fácies, com a finalidade de caracterizar o sistema deposicional. A análise de perfis de sondagem possibilitou também melhor compreensão dos padrôes arquiteturais da Formação Serra Alta, auxiliando na determinação de sua real distribuiçấo e posição estratigráfica na porçấo centro-sul do estado. A integração das informaçóes obtidas permitiu identificar tendências de empilhamento transgressivo particulares, contribuindo para o detalhamento da sucessão predominantemente regressiva em que se depositaram as unidades permianas da Bacia do Paraná.
\end{abstract}

PALAVRAS-CHAVE: Formação Serra Alta; sedimentologia; estratigrafia; paleontologia; Permiano; Bacia do Paraná.

\begin{abstract}
The delimitation and mapping of the Serra Alta Formation in the São Paulo State, Brazil, has always been a focus of controversy in the Brazilian geological community. Despite its large extension in subsurface, which may be comparable to the Irati Formation, the Serra Alta Formation still needs more detailed studies on its stratigraphic position, fossil content, depositional systems and age. In the east-central portion of the São Paulo State, the Serra Alta Formation overlies the Irati Formation and is predominantly composed of dark grey pelitic facies. The unit is mapped from the southern boundary of the São Paulo State to the Giboia Dome, located in the county of Rio das Pedras. In this place, the Serra Alta and Teresina formations are replaced by the red colored pelites of the Corumbatai Formation, unit that extends to north beyond the state boundaries and may be considered correlated to these units. In this work, we present columnar sections and describe the contacts of the Serra Alta Formation with vertically adjacent Permian units. We also present the detailed facies analysis, in order to characterize the depositional system. The investigation of subsurface profiles also enabled a better understanding of the architectural patterns of the succession, helping to determine its real distribution and stratigraphic position in the central-south of Säo Paulo State. The integration of the data allowed identifying a particular transgressive stacking pattern, contributing to detail the late Permian regressive cycle in the Paraná Basin.
\end{abstract}

KEYWORDS: Serra Alta Formation; sedimentology; stratigraphy; paleontology; Permian; Paraná Basin.

${ }^{1}$ Instituto de Geociências e Ciências Exatas, Universidade Estadual Paulista “Júlio de Mesquita Filho” - UNESP, Cidade (SP), Brasil. E-mails: warren@rc.unesp.br; assine@rc.unesp.br

²Departamento de Zoologia, Instituto de Biociências, Universidade Estadual Paulista “Júlio de Mesquita Filho” - UNESP, Cidade (SP), Brasil. E-mail: btsimoes@ibb.unesp.br 3Instituto de Energia e Ambiente e Instituto de Geociências, Universidade de São Paulo - USP, São Paulo (SP), Brasil. E-mails: riccomin@usp.br; anelli@usp.br *Autor correspondente.

Manuscrito ID: 30200. Recebido em: 10/11/2014. Aprovado em: 11/02/2015. 


\section{INTRODUÇÃO}

Desde sua definição como unidade litoestratigráfica formal (Sanford \& Lange 1960; Schneider et al. 1974), a Formação Serra Alta figura como uma das unidades menos estudadas da Bacia do Paraná. A análise crítica da literatura do Grupo Passa Dois mostra a inexistência de critérios estratigráficos claros para a delimitação dessa unidade no Estado de Sáo Paulo, bem como a ausência de estudos de fácies sedimentares consistente com suas particularidades (Meglhioratti 2006).

Devido à sua espessura reduzida no Estado de São Paulo, a Formação Serra Alta foi, durante muitos anos, incluída como parte de outras unidades litoestratigráficas ou, simplesmente, desconsiderada como unidade formal de mapeamento (Loczy 1966; IPT 1981). Na porção centro-leste do Estado de São Paulo, os estratos pertencentes à sucessão da Formação Serra Alta foram inicialmente incluídos nas camadas basais da Formação Estrada Nova e, posteriormente, incorporados na Formação Corumbataí. Como resultado da utilizaçáo de denominaçóes litoestratigráficas diversas para a mesma seção estratigráfica, importante conteúdo fossilífero pertencente à sucessão neopermiana da Bacia do Paraná, especialmente conchas de moluscos bivalves (Mendes 1952; Runnegar \& Newell 1971; Simóes \& Fittipaldi 1987), presente na Formação Serra Alta, foi posicionado, em alguns trabalhos, na porção inferior da Formação Corumbataí (Maranhão \& Petri 1996; Simóes \& Torello 2003). As incongruências nos critérios de individualização litoestratigráfica das formações Serra Alta, Teresina e Corumbataí, que resultam na aplicação de diferentes denominaçóes para a mesma seção sedimentar, apontam para a necessidade de revisão da litoestratigrafia do Grupo Passa Dois no Estado de Sáo Paulo.

Considerando o exposto, propóe-se neste artigo uma abordagem integrada dos aspectos sedimentares e estratigráficos da Formação Serra Alta, buscando-se a interpretação de seu sistema deposicional e sua relação de contato com outras unidades neopermianas do Grupo Passa Dois na faixa aflorante no Estado de São Paulo. Com base em resultados obtidos no estudo detalhado de afloramentos e de testemunhos de perfis de sondagem e do conteúdo fossilífero, apresenta-se aqui um modelo de sucessão vertical de fácies para a Formação Serra Alta, além de sugestôes para a ordenação litoestratigráfica para as unidades neopermianas no Estado de São Paulo.

A área estudada compreende a faixa de afloramento das unidades permianas do Grupo Passa Dois na porção centro-leste do Estado de São Paulo (Fig. 1). As melhores exposiçôes analisadas encontram-se em pedreiras ativas nas cercanias dos municípios de Rio Claro, Ipeúna e Charqueada, bem como em cortes na Rodovia Castello
Branco (SP-280), nos municípios de Cesário Lange, Torre de Pedra e Porangaba. Seçóes colunares e afloramentos também foram descritos em exposiçóes localizadas nos municípios de Laranjal Paulista, Rio das Pedras e Conchas.

\section{ESTRATIGRAFIA DA FORMAÇÃO SERRA ALTA}

A seção de cerca de $50 \mathrm{~m}$ de pelitos localizados na porção superior da Formação Irati foi originalmente incluída por White (1908) nos denominados "Schistos Estrada Nova”. Moraes Rego (1930) elevou essa sucessão à categoria de grupo (Grupo Estrada Nova) e Gordon Junior (1947) a definiu como formação nos estados do sul do Brasil, subdividindo-a nos membros Serra Alta e Teresina. A definição da Formação Serra Alta coube a Sanford e Lange (1960), que a consideraram como a sucessão de pelitos escuros delimitados verticalmente pelas formaçóes Irati (base) e Teresina (topo), proposta endossada por Vieira (1973).

No trabalho de revisão litoestratigráfica da Bacia do Paraná realizado por Schneider et al. (1974), a Formação Serra Alta aparece de forma definitiva como unidade independente, constituindo os estratos basais do Grupo Passa Dois (Mendes 1967). Apesar de alguns trabalhos terem utilizado, posteriormente, a nomenclatura de Vieira (1973) com respeito à alocação da Formação Serra Alta no "Grupo" ou "Formação Estrada Nova" (Sousa 1985; Maranhão \& Petri 1996), a proposta litoestratigráfica de Schneider et al. (1974) tem sido a mais utilizada até os dias atuais (Milani et al. 2007; Holz et al. 2010).

A Formação Serra Alta faz parte da seção do Permiano Superior da Bacia do Paraná (Sanford \& Lange 1960; Brito 1982; Schneider et al. 1974), ocorrendo imediatamente sobreposta à Formação Irati. Diferentes palinomorfos identificados nas formaçôes Irati e Serra Alta são atribuídos à Zona L2 de Daemon e Quadros (1970), também correspondente à Zona Lueckisporites virkkiae (Marques-Toigo 1988), ambas de idade neopermiana, atualmente abrangendo o Wordiano e Changhsingiano. A presença de mesossaurídeos nas formações Irati e Whitehill (África do Sul) permite estabelecer a correlação entre essas unidades e atribuir idade Artinskiana para a deposição de ambas (Lages 2004). Idades por volta de $275 \mathrm{Ma}$ obtidas por Rocha-Campos et al. (2011) para camadas de cinza presentes no topo da Formação Irati sugerem que o topo dessa unidade se depositou no início da Época Kunguriana, o que necessariamente implica que a sedimentação da Formação Serra Alta é mais nova que $275 \mathrm{Ma}$. Para as unidades sobrepostas à Formação Serra Alta, Rocha-Campos et al. (2011) obtiveram idades de $267 \pm 17$ Ma para a Formação Teresina e 
de 266,3 \pm 4,6 Ma para a Formação Rio do Rasto. Esses dados permitem posicionar a deposição da unidade na época Guadalupiana (Wanke 2000; Holzfoerster 2002).

Segundo Barberena et al. (1985), a presença de Pareiasaurus americanus nos estratos da Formação Rio do Rasto permite a correlação com a biozona Capitaniana "Daptocephalus" da Bacia do Karoo (África do Sul). Considerando-se a macrofauna de vertebrados, é possível a proposição de idade Capitaniana aproximada para a Formação Rio do Rasto e Artinskiana para a Formação Irati, o que define intervalo de, no máximo, 30 Ma para as formaçôes Serra Alta e Teresina (290 a 260 Ma).

A conjugação de dados palinológicos com as biozonas definidas para os vertebrados fósseis restringe a deposição dos estratos que compóem a Formação Serra Alta para um intervalo ao redor de $3 \mathrm{Ma}$, delimitado entre as idades Capitaniana inferior (265 Ma) e Wordiana inferior (268 Ma), pertencentes a porção intermediária a superior da Época Guadalupiana (Fig. 2; 268,8 a 259,9 Ma; Daemon \& Quadros 1970; Barberena et al. 1985; Lages 2004; López-Gamundí 2006; Santos et al. 2006; Rocha-Campos et al. 2011).
O contato entre as formaçóes Serra Alta e Teresina é considerado transicional (Castro et al. 1993; Hachiro 1996; Araújo 2001), materializando mudança gradual de ambiente profundo pouco oxigenado para ambiente de águas cada vez mais rasas e agitadas (Mendes 1984). A deposição em águas proximais seria registrada pelas fácies heterolíticas bioturbadas e pela coloração avermelhada dos sedimentos (Rohn 2001; Rohn et al. 2003; Meglhioratti 2006; Duque 2012). Em subsuperfície, o contato é marcado pela diminuição dos valores de radioatividade nos raios gama, resultado direto do aparecimento de camadas de areias finas e/ou carbonatos típicos da Formação Teresina.

O contato inferior tem sido historicamente descrito como transicional, marcado pelo desaparecimento de folhelhos e carbonatos da Formação Irati e pelo aparecimento gradual de siltitos laminados de cor cinza característicos da Formação Serra Alta (Maack 1947; Beurlen 1954; Castro et al. 1993). No entanto, para alguns autores, essa passagem é de difícil reconhecimento devido às semelhanças litológicas (Mezzalira 1971), especialmente nos Estados do Paraná e Santa Catarina (Lavina 1991; Warren 2005).

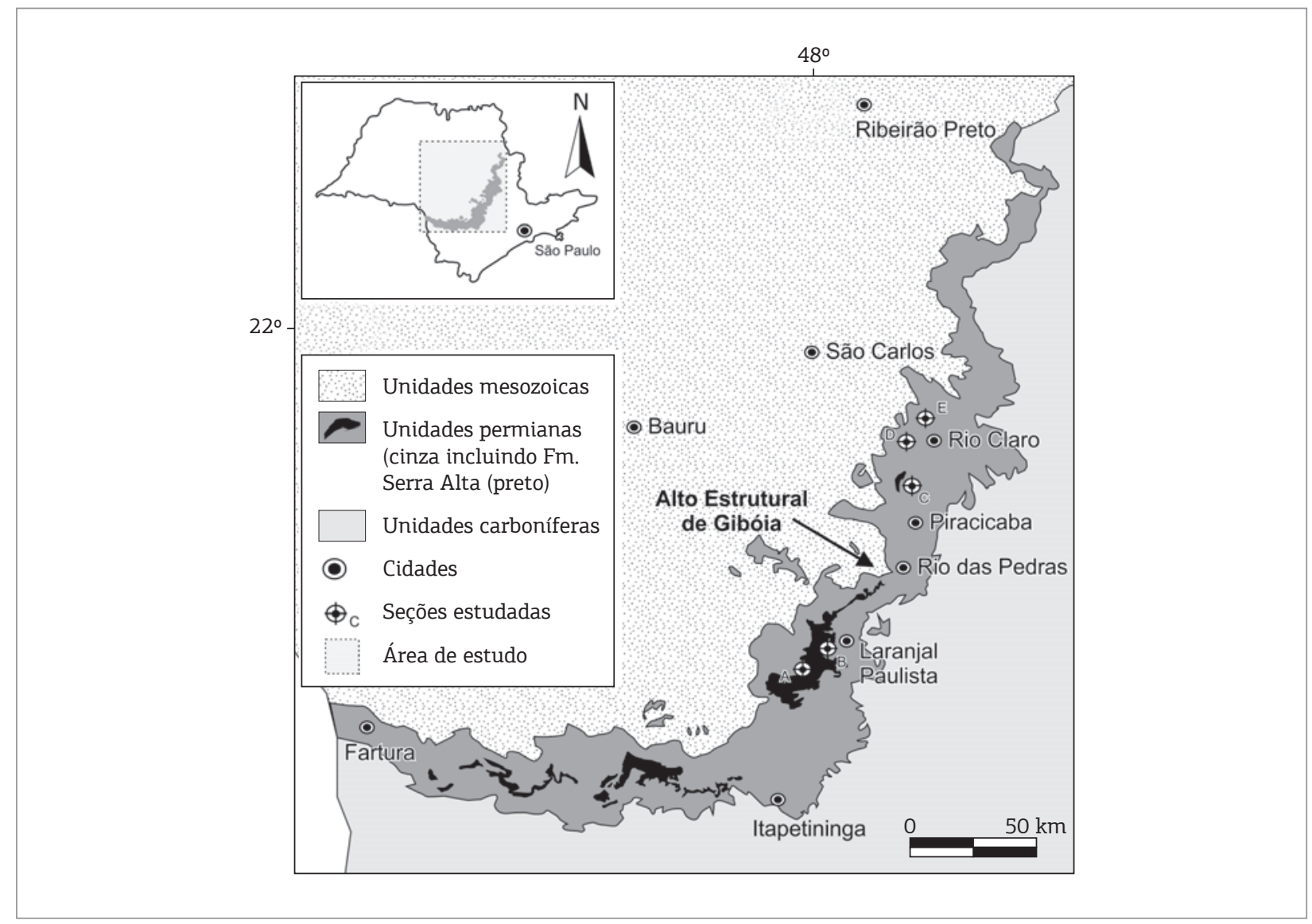

Figura 1. Mapa geológico esquemático destacando a faixa de afloramentos de rochas da sucessão permiana da Bacia do Paraná no Estado de São Paulo. Notar os fragmentos e a faixa descontínua e delgada que caracterizam os limites cartográficos da Formação (Fm) Serra Alta (baseado em IPT 1981; CPRM 1999, 2006). 


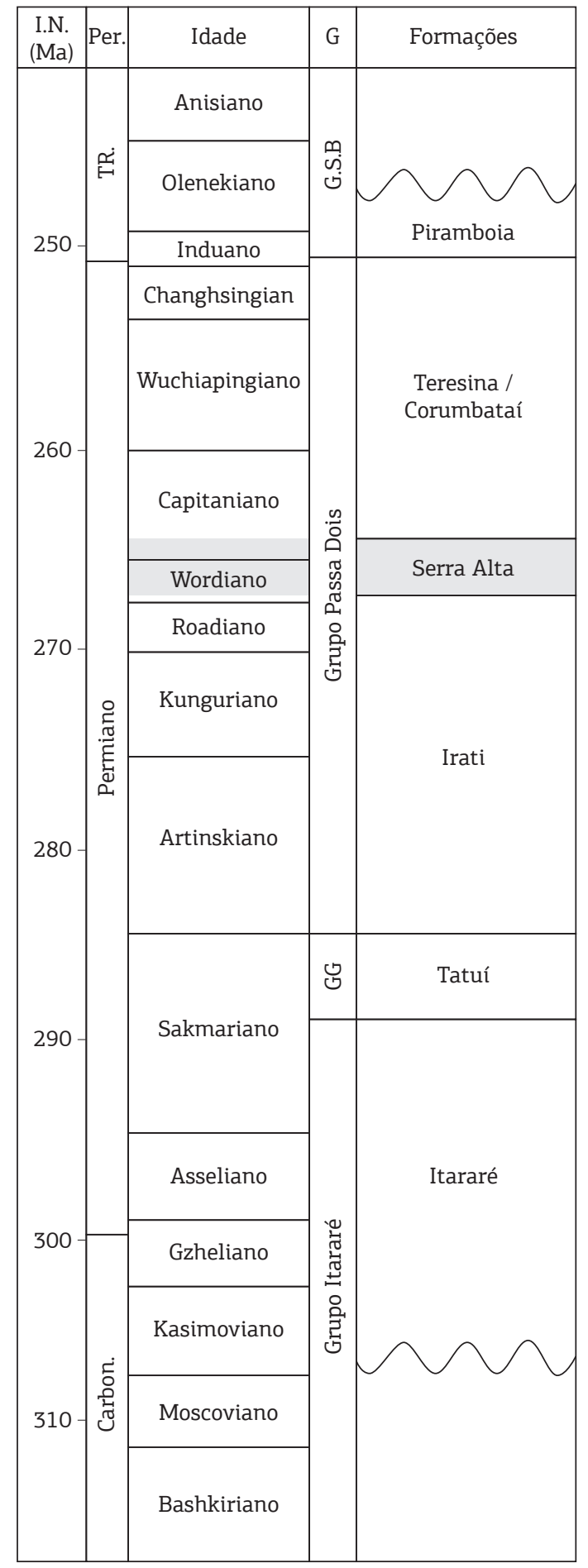

Nota: As idades das unidades foram recompiladas a partir de dados paleontológicos e geocronológicos de Daemon e Quadros (1970), Barberena et al. (1985), Lages (2004), López-Gamundí (2006), Santos et al. (2006) e Rocha-Campos et al. (2011).

I.N.: idade numérica; Per.: período; G: Grupo; TR.: Triássico; GSB: Grupo São Bento; GG: Grupo Guatá; Carbon.: Carbonífero. Fonte: baseado em Milani et al. 2007; Holz et al. 2010.

Figura 2. Arcabouço cronoestratigráfico do Paleozoico superior da Bacia do Paraná destacando a faixa de tempo em que se depositou a Formação Serra Alta.
Em subsuperfície, perfis de sondagem indicam que o limite entre as formaçôes Irati e Serra Alta é notadamente marcado por um pico radioativo nos perfis de raios gama que se estabiliza em um patamar definido (Lages 2004). O desaparecimento das camadas de carbonatos e a presença de folhelhos negros provocam uma incursão positiva nos perfis de raios gama e podem ser considerados como o contato das duas unidades em subsuperfície. Desse modo, a definição da última camada de carbonato da Formação Irati como limite litoestratigráfico (de maneira antagônica a proposta de Hachiro 1996 e Araújo 2001) é justificada pela completa ausência de camadas carbonáticas decimétricas na porção basal da Formação Serra Alta.

Gama Junior (1979) sugeriu um modelo integrado para o Grupo Passa Dois, postulando a evolução de um delta de grandes dimensôes no qual as rochas da Formação Serra Alta corresponderiam a depósitos de plataforma nerítica, os litotipos da Formação Teresina ao prodelta e as camadas da Formação Rio do Rasto estariam associadas à planície e frente deltaicas. Tal interpretação, segundo Lavina (1991), embora embasada em dados confiáveis, náo foi amplamente adotada em trabalhos posteriores. Segundo Schneider et al. (1974), a sedimentação das camadas da Formação Serra Alta teria ocorrido em condiçôes similares às do Membro Taquaral (Formação Irati), ou seja, em águas calmas abaixo do nível de base de ondas, em áreas fisiograficamente restritas de um grande corpo d'água interior.

Dentro do modelo estratigráfico apresentado neste trabalho, a Formação Serra Alta compóe uma sucessão com espessura média de 50 m (Figs. 3 e 4) constituída predominantemente por fácies siliciclásticas finas e depositada sobre uma desconformidade erosiva (diastema) presente no topo da Formação Irati.

Com base em testemunhos de sondagens, Meglhioratti (2006) considerou que a Formação Serra Alta apresenta uma espessura média da ordem de $52 \mathrm{~m}$ no sudoeste do Estado de São Paulo. No Estado do Paraná, dados de sondagens nas proximidades da faixa aflorante registram espessura máxima de $68 \mathrm{~m}$ (Rohn et al. 2003), mas trabalhos regionais apontam tendência de aumento de espessura para sul (Milani \& Ramos 1998), não ultrapassando, porém, os $100 \mathrm{~m}$ (Meglhioratti 2006).

A Formação Serra Alta aparece como unidade formal de mapeamento no Estado de São Paulo, pela primeira vez, no mapa geológico compilado pelo Instituto de Pesquisas Tecnológicas (IPT 1981). Do ponto de vista litoestratigráfico, a Formaçáo Serra Alta no estado corresponde a uma sucessão constituída por siltitos cinza médio/escuros a pretos, posicionados acima da última camada de 


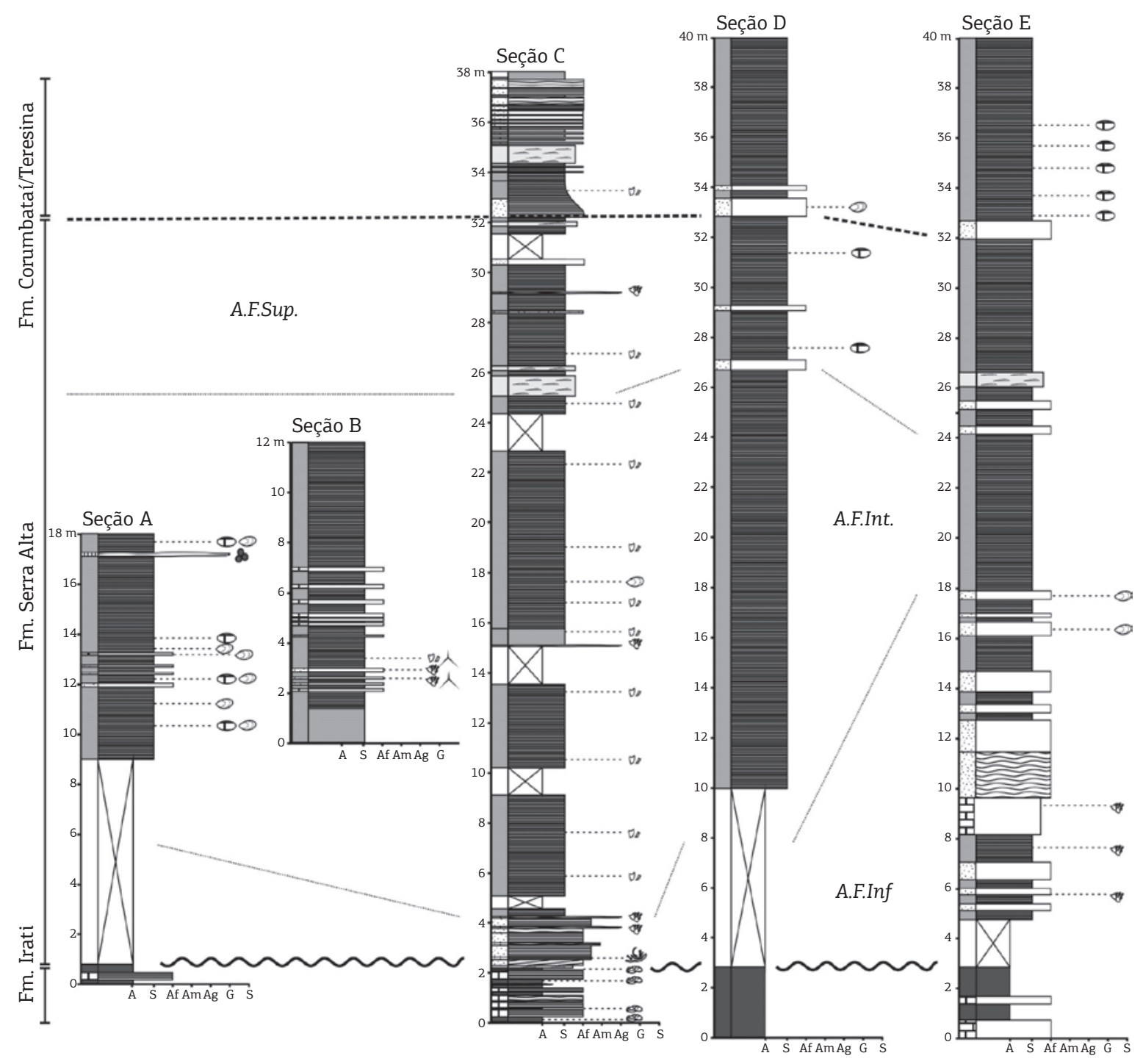

\begin{tabular}{|c|c|c|c|}
\hline Litogias & Estruturas sedimentares & Fósseis & Outras feições \\
\hline בד Dolomito & 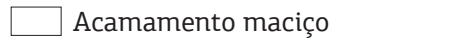 & (2) Bivalves & Nódulos de sílex \\
\hline Arenito & Eaminação plano-paralela & (Restos fósseis de & 8. Nódulos fosfáticos \\
\hline Folhelho & $\approx$ Laminação cruzada por onda & Mesossaurídeos & Concreções carbonáticas \\
\hline Siltito & Acamamento heterolítico & 入 Espículas de esponja & "'"' Contato transicional \\
\hline Arenito/Siltito & $\exists$ Estratificação cruzada acanalada & $\begin{array}{l}\text { HEO Coprólitos e restos } \\
\text { fósseis de peixes }\end{array}$ & 〜 Discordância erosiva \\
\hline & & $\nabla_{\Delta} \begin{array}{l}\text { Restos fósseis de } \\
\text { peixes dispersos }\end{array}$ & \\
\hline
\end{tabular}

A.F.Sup.: associação de fácies superior; A.F.Int.: associação de fácies intermediária; A.F.Inf.: associação de fácies inferior; A: argila; S: silte; Af: areia fina; Am: areia média; Ag: areia grossa; G: grânulo; S: seixo.

Figura 3. Seções colunares da Formação Serra Alta no Estado de São Paulo. Destaque para a seção-tipo da unidade (seção A) adquirida na Pedreira Partecal-Partezani, município de Rio Claro (SP). Notar a presença de fácies arenosas na base. 


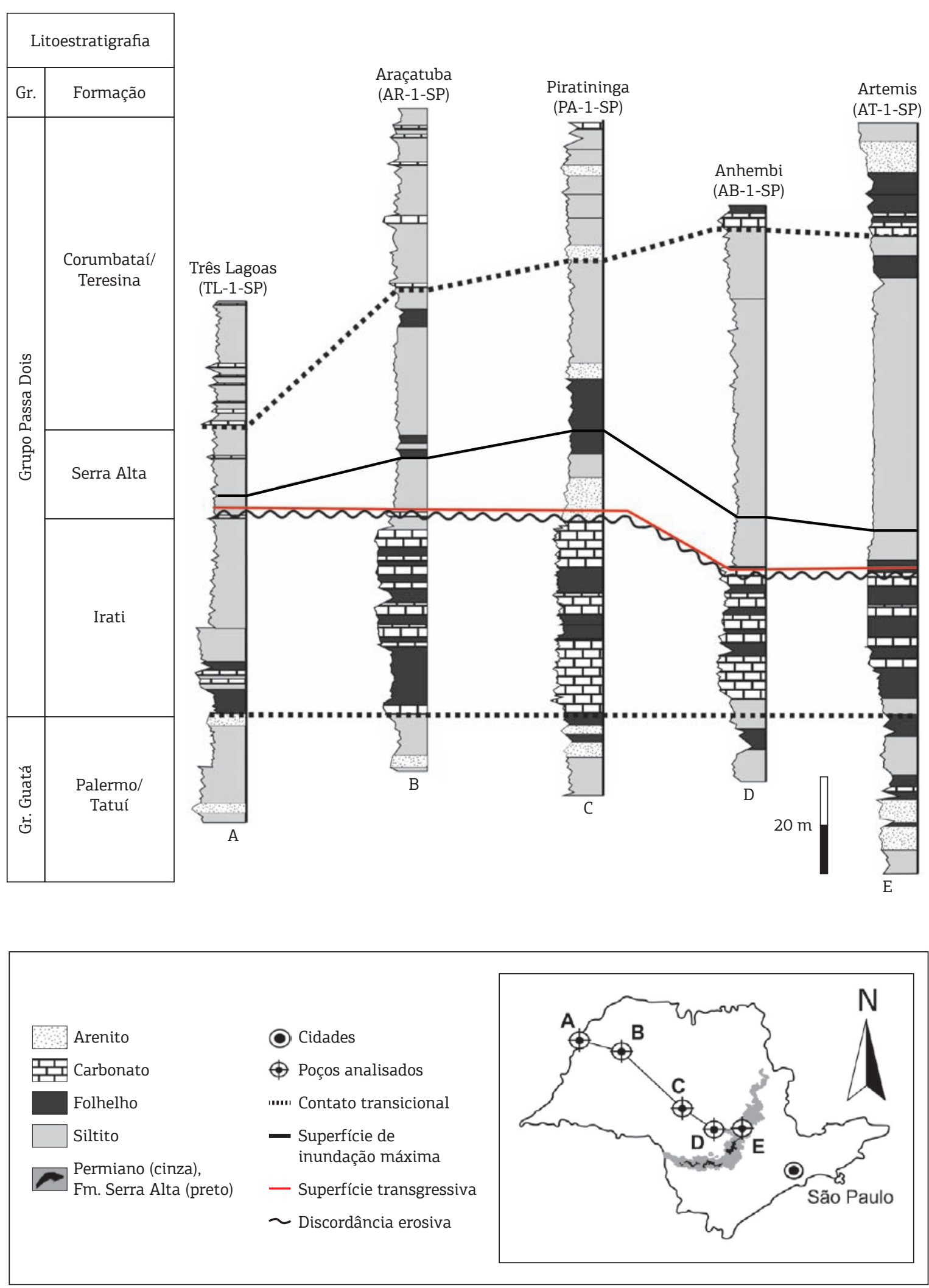

Gr: Grupo; Fm: Formação.

Figura 4. Perfis de poços analisados no Estado de São Paulo destacando os estratos da Formação Serra Alta. Notar o adelgaçamento e a diminuição da proporção de folhelhos da unidade para oeste. 
rochas carbonáticas da Formação Irati e abaixo da primeira camada decimétrica de arenitos e/ou rochas carbonáticas da Formação Teresina. Com espessura inferior a $60 \mathrm{~m}$, a Formação Serra Alta constitui estreita faixa de afloramentos que desaparece no centro do estado (IPT 1981; CPRM 2006). Nos mapas geológicos disponíveis para o estado, as formaçóes Serra Alta e Teresina são mapeadas desde os limites com o Estado do Paraná até aproximadamente o alto estrutural conhecido como Domo de Gibóia, a oeste do município de Rio das Pedras (IPT 1981; CPRM 1999, 2006). A nordeste do Domo de Gibóia, a seção correspondente às formaçóes Serra Alta e Teresina é mapeada com a denominação de Formação Corumbataí (Fig. 1).

\section{RESULTADOS}

A análise faciológica da Formação Serra Alta está fundamentada na descrição de fácies sedimentares, levando-se em conta variáveis como composição mineralógica, granulação, estruturas sedimentares primárias e conteúdo fossilífero. Para todas as fácies, foram interpretados os processos deposicionais, tendo como base os processos físicos de sedimentação (Tab. 1). As fácies foram agrupadas em três associações

Tabela 1. Fácies sedimentares da Formação Serra Alta.

\begin{tabular}{|c|c|c|c|}
\hline Código & Fácies & Descrição & Interpretação \\
\hline Sl & Siltito laminado & $\begin{array}{l}\text { Fácies de siltitos laminados lateralmente } \\
\text { persistentes, em sucessões com até } 10 \text { m de } \\
\text { espessura. Apresenta cor cinza escura a preta } \\
\text { e matizes claras (creme a amarelo) quando } \\
\text { alterada. Pode apresentar nódulos carbonáticos } \\
\text { e concreções discoides centimétricas a } \\
\text { decimétricas associadas ou não à presença de } \\
\text { bivalves fósseis. São comuns restos de peixes } \\
\text { (escamas, dentes e ossos), coprólitos e raros } \\
\text { fragmentos vegetais e bivalves alóctones. }\end{array}$ & $\begin{array}{l}\text { Deposição por decantação em } \\
\text { condições de águas calmas, } \\
\text { disóxicas ou anóxicas. }\end{array}$ \\
\hline $\mathrm{F}$ & Folhelhos & $\begin{array}{l}\text { Folhelhos cinza escuros a pretos, em } \\
\text { camadas com continuidade lateral e } \\
\text { espessura decamétrica, podendo apresentar } \\
\text { concreções carbonáticas discoides e } \\
\text { expressivo conteúdo fóssil disperso. }\end{array}$ & $\begin{array}{l}\text { Decantação de argilas em } \\
\text { águas calmas. A coloração } \\
\text { escura sugere condições } \\
\text { redutoras no sítio deposicional. }\end{array}$ \\
\hline $\mathrm{H}$ & Fácies heterolítica & $\begin{array}{l}\text { Camadas centimétricas a decimétricas de } \\
\text { arenitos finos interestratificados com pelitos, } \\
\text { com coloração variando de cinza clara a rosa, } \\
\text { predominando o acamamento wavy e linsen, } \\
\text { com recobrimento das calhas e cristas de } \\
\text { laminação cavalgante por lâminas de argila. }\end{array}$ & $\begin{array}{l}\text { Depósitos formados por alternância } \\
\text { nas condições de decantação e } \\
\text { recorrência de correntes com } \\
\text { transporte por suspensão/tração. }\end{array}$ \\
\hline $\mathrm{Al}$ & $\begin{array}{l}\text { Arenito com laminação } \\
\text { plano-paralela }\end{array}$ & $\begin{array}{l}\text { Arenitos muito finos, bem selecionados, } \\
\text { com laminação plano-paralela, em camadas } \\
\text { tabulares, centimétricas a decimétricas. }\end{array}$ & $\begin{array}{l}\text { Deposição por fluxos de fundo } \\
\text { em leito plano em regime } \\
\text { de fluxo inferior. }\end{array}$ \\
\hline Am & Arenito maciço & $\begin{array}{c}\text { Camadas centimétricas tabulares, ou lenticulares, } \\
\text { de arenitos muito finos, bem selecionados, } \\
\text { localmente com estruturas de liquefação. }\end{array}$ & $\begin{array}{l}\text { Fluxos de fundo originados por } \\
\text { correntes associadas a ondas } \\
\text { anormais ou tempestades. }\end{array}$ \\
\hline Alc & $\begin{array}{l}\text { Arenito com laminação } \\
\text { cruzada por onda }\end{array}$ & $\begin{array}{l}\text { Arenitos tabulares, em camadas } \\
\text { centimétricas a decimétricas, muito } \\
\text { finos a finos, bem selecionados, com } \\
\text { laminações truncadas por ondas. }\end{array}$ & $\begin{array}{l}\text { Retrabalhamento dos sedimentos } \\
\text { de fundo por ondas. }\end{array}$ \\
\hline Aca & $\begin{array}{l}\text { Arenito com estratificação } \\
\text { cruzada acanalada }\end{array}$ & $\begin{array}{l}\text { Arenitos finos, bem selecionados, em camadas } \\
\text { tabulares decimétricas, com estratificação } \\
\text { cruzada acanalada de pequeno porte. O sedimento } \\
\text { é bem selecionado e de coloração creme. }\end{array}$ & $\begin{array}{l}\text { Migração de formas de leito } \\
\text { subaquosas de crista sinuosa } \\
\text { devido à ação continuada de } \\
\text { correntes unidirecionais. }\end{array}$ \\
\hline C & Coquinas & $\begin{array}{l}\text { Fácies caracterizada pela concentração } \\
\text { de fragmentos fosfatizados de ossos, } \\
\text { escamas, dentes e coprólitos, com baixa } \\
\text { seleção granulométrica e empacotamento } \\
\text { variando de frouxo a denso. }\end{array}$ & $\begin{array}{l}\text { Acúmulo em eventos de alta } \\
\text { energia (tempestades), devido ao } \\
\text { carreamento de fragmentos fósseis } \\
\text { por correntes de retorno, formando } \\
\text { depósitos residuais (lags). }\end{array}$ \\
\hline
\end{tabular}


distintas, que se sucedem na vertical e são referidas de acordo com a posição estratigráfica que ocupam no empilhamento vertical da Formação Serra Alta, como associações de fácies inferior, intermediária e superior.

Na maior parte das seçôes estratigráficas analisadas, a formação apresenta em sua porção inferior camadas decimétricas a métricas de arenitos finos com laminaçáo cruzada, com níveis de concentraçáo de fragmentos de ossos e escamas de peixe (bone beds). Essas fácies são sucedidas $-20 \mathrm{~m}$ de pelitos laminados cinza, correspondentes à associação de fácies intermediária, a mais característica da unidade. Os estratos da porçáa superior da Formaçáo Serra Alta sáo caracterizados pela mudança de tonalidade do cinza para o rosa e o vermelho e presença de fácies heterolíticas, constituídas por pelitos intercalados com arenitos finos.

Ressalta-se que seçóes completas nas quais estáo expostos o topo e a base da Formação Serra Alta são raras. A seção colunar levantada na Pedreira Partecal, localizada no Município de Rio Claro (SP), é a mais completa, apresentando toda a sucessão vertical de fácies (Fig. 3).

\section{Associação de fácies inferior}

A porção inferior da Formação Serra Alta é caracterizada por um intervalo de aproximadamente $2 \mathrm{~m}$ de espessura, constituído por camadas centimétricas a decimétricas de arenitos muito finos (Figs. 3 e 5A). Essas camadas foram identificadas em algumas exposiçóes nos municípios de Rio Claro, Piracicaba, Limeira e Ipeúna, tendo sido anteriormente constatadas por Soares e Landim (1973). Predominam camadas decimétricas tabulares de arenitos finos a médios com estratificação cruzada acanalada de pequeno porte, laminaçáo cruzada com truncamentos por onda e laminaçáo plano-paralela (fácies Aca, Alc, Al), com intercalaçóes de níveis centimétricos lenticulares de coquinas constituídas por restos de crustáceos, escamas, dentes e ossos de peixes provenientes da desestruturação de coprólitos (fácies C). Esses níveis sustentados por bioclastos são comuns logo acima da base da unidade, lateralmente sendo reconhecidos por quilômetros em diversas exposiçóes nos municípios de Ipeúna e Rio Claro. As fácies Al são também marcadas pela presença de fragmentos dispersos de ossos fosfatizados de mesossaurídeos, registro de que restos retrabalhados desses répteis encontram-se presentes na Formação Serra Alta (Fig. 3). As fácies Al indicam processos de deposição por fluxos de fundo em regime inferior em leito plano abaixo do nível de base das ondas de tempo bom, possivelmente em condiçóes de shoreface inferior à transição para offshore. Essa associaçáo é de ocorrência esporádica em subsuperfície, sugerindo que esta desaparece para oeste do Estado de Sáo Paulo (Fig. 4).

A associaçáo é caracterizada também pela presença de camadas de arenitos finos com laminaçáo cruzada por ondas (fácies Alc), interpretadas como representativas do processo de migração de ondulaçôes/ripples com cristas sinuosas (Fig. 5B). Essas formas de leito migram a partir da ação de correntes ou orbitais de fundo que revolvem o substrato marinho em ocasióes de tempestades (Clifton 2006). Raras camadas apresentando estratificaçáo cruzada (fácies Aca) são interpretadas como produto da migraçáo de formas de leito de crista sinuosa pela ação de correntes unidirecionais de fundo. Estas se formam durante eventos energéticos episódicos que possibilitam a atuação de correntes e o retrabalhamento do fundo marinho em condiçôes de shoreface inferior à transição para offshore.

Níveis centimétricos sustentados por bioclastos de escamas, dentes, ossos e coprólitos de peixe (Fig. 5C) indicam que os restos retrabalhados foram concentrados por joeiramento (winnowing), induzido pela subida do nível relativo do mar. Esse evento de caráter transgressivo formou concentraçôes bioclásticas residuais do tipo lag, contendo material fóssil erodido, retrabalhado e/ou trazido por correntes e ondas atuantes na regiáo costeira. A presença de esqueletos desarticulados de mesossaurídeos na fácies $\mathrm{Al}$, logo acima da base da Formação Serra Alta, indica retrabalhamento de camadas superiores da Formação Irati (Fig. 5D). A extensấo lateral desses níveis é sugestiva de deposição abaixo do nível de base de ondas de tempo bom.

Nas fácies arenosas basais, foram observados cristais hexagonais ou losangulares com sulco mediano longitudinal (Fig. 5E), interpretados como pseudomorfos de gipsita, cuja presença pode ser devido à neoformaçấo em condiçóes ambientais de alta salinidade ou cristalizaçâo durante os estágios iniciais da eodiagênese sob influência de fluidos salinos.

\section{Associação de fácies intermediária}

A associação de fácies intermediária é uma sucessão monótona de aproximadamente $20 \mathrm{~m}$ constituída por folhelhos e siltitos laminados cinza escuros (fácies $\mathrm{F} \mathrm{e} \mathrm{Sl}$ ), recobrindo as fácies psamiticas inferiores ou, em alguns locais, assentando-se diretamente sobre estratos da Formação Irati. Esses pelitos constituem a feição mais característica da Formação Serra Alta, ocorrendo em todas as seçôes da unidade nos Estados de São Paulo, Paraná, Santa Catarina e Rio Grande do Sul, com aumento significativo de sua espessura para oeste e sul (Soares \& Landim 1973; Schneider et al. 1974; Mezzalira 1971; Rohn 2001; Meglhioratti 2006; Warren et al. 2008). A fácies Sl (Fig. 5F) é produto da decantação de sedimentos finos abaixo do nível de base das ondas de tempestade. A coloração escura indica teores elevados de matéria orgânica, sugerindo que a decantaçáo dos sedimentos ocorreu num extenso corpo d'água com condiçôes redutoras no fundo. A incidência pontual de bioturbação e de cristais euhédricos de pirita nos siltitos laminados e nos folhelhos (Meglhioratti 

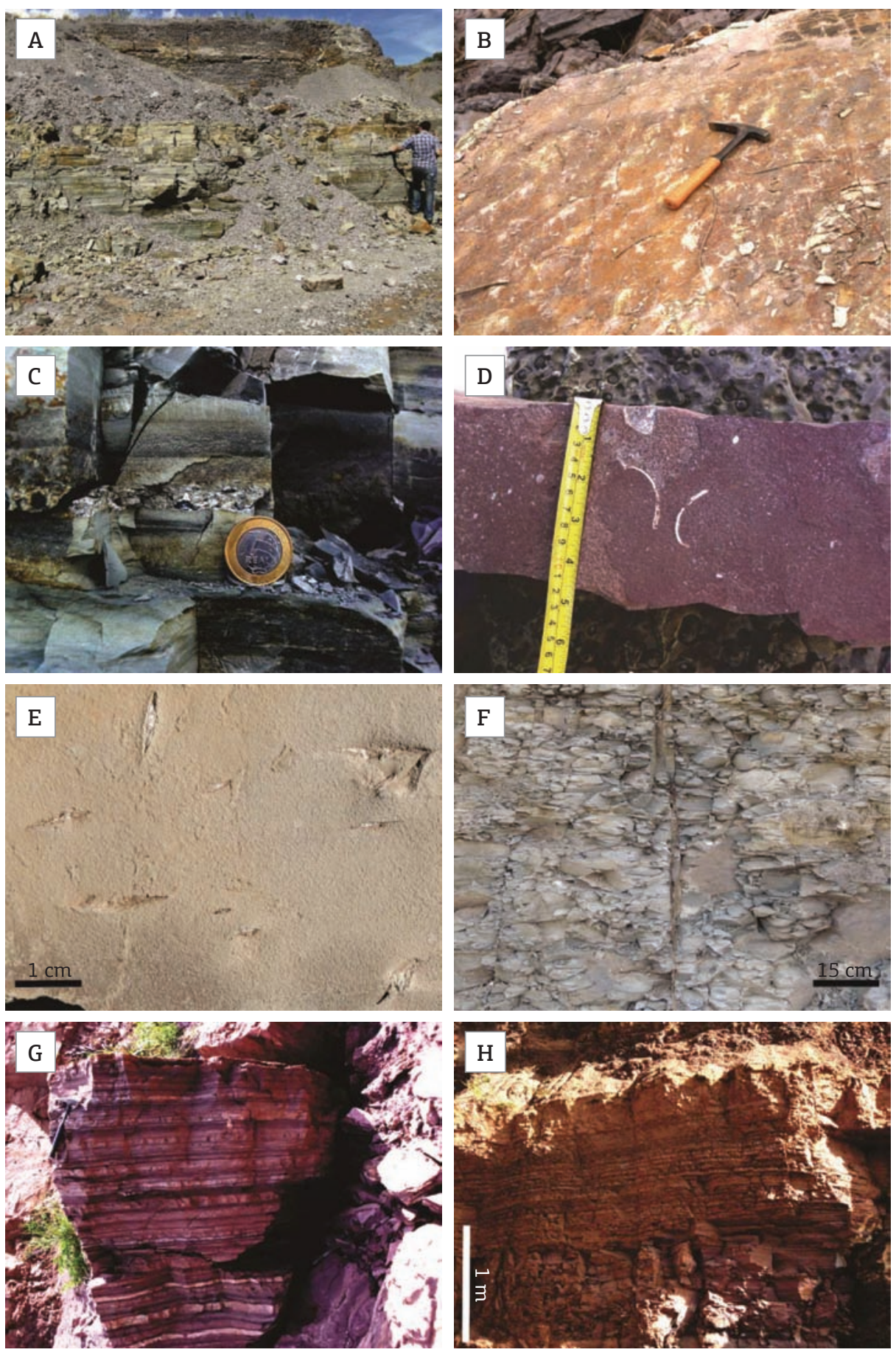

Figura 5. Fácies sedimentares da Formação Serra Alta. (A) Afloramento de fácies arenosas basais da Formação Serra Alta. Notar que, sobre esse nível, ocorre espessa camada de siltitos cinza laminados correspondentes à associação de fácies intermediária da unidade. (B) Detalhe de marcas onduladas em arenitos da base da Formação Serra Alta (fácies Alc). (C) Depósitos centimétricos de níveis de coquinas bioclasto suportadas. Estas ocorrem principalmente na base da Formação Serra Alta e podem ser acompanhadas lateralmente por quilômetros. (D) Fragmentos de costelas de mesossaurídeos em fácies de arenitos laminados presentes na base da unidade. (E) Detalhe de cristais de gipsita losangulares com sulco mediano longitudinal. (F) Detalhe de fácies de siltitos cinza laminados (fácies Sl). (G) Fácies heterolíticas do tipo wavy (fácies $\mathrm{H}$ ) de coloração avermelhada típica da associação de fácies superior da Formação Serra Alta. (H) Detalhe de camadas tabulares arenosas decimétricas características do contato superior da Formação Serra Alta com a Formação Teresina. 
2006) reforça a hipótese de que a deposição e a eodiagênese ocorreram em condiçóes predominantemente redutoras.

A presença ocasional de lâminas de arenitos finos, com ou sem fragmentos de fósseis, está associada à deposição episódica por fluxos trativos de fundo. Não foram observadas feiçóes sugestivas de retrabalhamento, tais como superfícies de escavação e/ou retrabalhamento por ondas, o que indica que a fácies Am se depositou abaixo do nível de base de ondas de tempestade, por correntes de fundo associadas a tempestades em condiçóes de costa-afora (offshore).

Níveis centimétricos de coquinas (fácies C; Fig. 5C), intercalados nos sedimentos finos dessa associação, são também interpretados como depósitos produzidos em eventos episódicos associados a tempestades, durante as quais fósseis de porçóes proximais são transportados para áreas mais profundas da bacia por correntes de fundo. Simóes e Torello (2003) interpretaram níveis fossilíferos semelhantes, presentes na base da Formação Corumbataí, como depositados por tempestades, durante as quais correntes de retorno carreariam fósseis para águas profundas e distais (Bondioli et al. no prelo). Nessa interpretação, níveis de coquina ou horizontes delgados contendo fragmentos fósseis (fácies $\mathrm{Sl}$ ) são produto de material retrabalhado por tempestades em ambientes de águas rasas e transportado para o interior da bacia por correntes de alta energia, com deposição rápida por decantação devido à desaceleração do fluxo, num processo semelhante à remobilização de material bioclástico para áreas mais profundas da bacia interpretada por Brett et al. (2012a, 2012b).

Em diferentes camadas, ocorrem estruturas nodulares irregulares constituídas por fragmentos cominuídos de peixes, incluindo ossos, escamas e dentes. Esses nódulos, que em perfil compóem corpos irregulares milimétricos a centimétricos compostos por material bioclástico, são interpretados como fragmentos de coprólitos parcialmente desagregados deformados pelo peso do sedimento, formando lentes densamente empacotadas e de distribuição irregular em planta.

\section{Associação de fácies superior}

A associação de fácies superior é caracterizada pela presença de fácies heterolíticas (fácies $\mathrm{H}$ ) com intercalaçôes de camadas tabulares centimétricas de arenitos com laminação plano-paralela (fácies Al). Os siltitos laminados rosados e avermelhados (fácies $\mathrm{Sl}$ ) diminuem em frequência em direção ao topo (Fig. $5 \mathrm{H}$ ). O arranjo estratigráfico mostra granodecrescência ascendente (Fig. 5G), reflexo de condiçóes progressivamente mais proximais em direção ao topo, o que caracteriza empilhamento regressivo progradacional. A direção e a velocidade desses fluxos de fundo são controladas pela topografia do fundo e pela direção da descarga injetada a partir de porçôes costeiras e se assemelhariam a correntes de turbidez com densidade superior à da água do corpo aquoso receptor (Lambert et al. 1976).

A mudança de coloração dos siltitos e folhelhos, de cinza característica para rosa clara e avermelhada, é indicativa de condiçôes ambientais progressivamente mais oxidantes (oxidação do ferro presente no sedimento durante a deposição e/ou eodiagênese). A presença de bioturbação nos níveis heterolíticos, com traços típicos da icnofácies Cruziana (Rohn 2001; Rohn et al. 2003), reforça a interpretação de deposição em fundo oxigenado.

A presença de fácies de águas mais rasas e o aumento gradativo de camadas de arenitos com espessuras decimétricas na porção superior da unidade indicam redução da lâmina d'água e diminuição do espaço de acomodação, consequência de aumento no aporte de sedimentos e/ou queda do nível do mar. É importante observar que, sobre o contato transicional da Formação Serra Alta com a Formação Corumbataí (Fig. 3), os dois primeiros metros correspondem a um ciclo de espessamento ascendente caracterizado pelo aumento na espessura das camadas tabulares das fácies $\mathrm{Al}$ e Am. Do ponto de vista litoestratigráfico, considera-se que a primeira camada decimétrica de arenitos laminados represente o contato entre o topo da Formaçáo Serra Alta e a base da Formação Corumbataí (Fig. 3).

\section{Registro fossilífero}

A assembleia de bivalves fósseis da Formação Serra Alta pertence à Biozona de Associação Barbosaia angulata-Anhembia froesi (Mezzalira 1966; Maranhão 1986; Simóes et al. 2000) que passa em direção ao topo para a Biozona de Associação Pinzonella illusa-Plesiocyprinella carinata, típica da porção média e superior da Formação Teresina, lateralmente equivalente à Formação Corumbataí no Estado de São Paulo (Rohn 1994; Simóes \& Torello 2003).

Fragmentos fosfatizados de escamas, dentes e ossos de peixes paleoniscídeos e ictiodontes, bem como coprólitos e peloides, são também comuns na porção inferior da Formação Serra Alta (Fig. 6A; Maranhão \& Petri 1996; Simões \& Rohn 1996). Esses fragmentos formam concentraçôes localizadas do tipo bone beds ou lentes delgadas sustentadas por bioclastos ou com empacotamento frouxo, compondo depósitos irregulares de espessura centimétrica e extensão lateral que pode atingir vários metros (fácies $\mathrm{C}$ ). Algumas dessas delgadas camadas apresentam estruturas indicativas de depósitos formados por tempestades, tais como gradação normal (Lavina 1991; Simóes \& Rohn 1996). Algumas concentraçóes de fragmentos, lenticulares ou disformes, sustentadas por bioclastos, ocasionalmente com forma botroidal, são aqui interpretadas como coprólitos desagregados (Fig. 6B), que possivelmente são formadas a partir de fezes de organismos de porte razoável (peixes?), desagregadas pela ação de 
correntes de fundo associadas a tempestades. Além da ocorrência dos fragmentos relacionados, verificou-se também a ocorrência de restos de mesossaurídeos retrabalhados nas camadas arenosas basais da Formação Serra Alta (Fig. 5D).

Os horizontes fósseis contendo representantes da malacofauna da Biozona de Barbosaia angulata são restritos vertical e lateralmente e, às vezes, ocorrem associados a lentes delgadas de arenito fino, interpretadas como produto da movimentação dos sedimentos de fundo pela ação de tempestades (Sousa 1985; Simóes et al. 2000; Bondioli 2014). Moluscos bivalves encontrados nos siltitos, tais como Tambaquyra camargoi (Fig. 7F), podem atingir grandes dimensóes, sugerindo breves pulsos de oxigenação de fundo e/ou aumento na disposição de nutrientes (Simóes et al. 2000). Além de restos de peixes, também é marcante a presença de ostracodes e espículas de esponja, ambos restritos às camadas de arenitos da porção superior da unidade (Maranhão \& Petri 1996). Embora de ocorrência restrita, lenhos de gimnospermas são descritos em fácies de pelitos laminados (Merlotti 2000).

\section{DISCUSSÃO}

As formaçôes Serra Alta e Teresina são reconhecidas e mapeadas, em superfície e subsuperfície, desde o sul do país até a região estudada no centro-leste do Estado de São Paulo. A Formação Teresina é caracterizada pela presença de pelitos, porém com predomínio de carbonatos oolíticos, coquinas e, ocasionalmente, estromatólitos. O contato entre as duas unidades é definido pelo primeiro aparecimento de camadas carbonáticas decimétricas presentes na Formação Teresina, muitas vezes constituídas por estromatólitos (Schneider et al. 1974; Simóes \& Torello 2003; Duque 2012).
As duas unidades deixam de ser cartografadas nos mapas existentes (IPT 1981; CPRM 1999, 2006) a norte do Domo de Gibóia (Munícipio de Rio das Pedras), sendo o intervalo estratigráfico correspondente mapeado no seu conjunto como Formação Corumbataí. Desta forma, as formaçôes Serra Alta e Teresina têm sido englobadas indistintamente, a norte do domo, sob a denominação Formaçáo Corumbataí (Sousa 1985; Maranhão \& Petri 1996; Meglhioratti 2006). Isso evidentemente causa problemas nas interpretaçóes estratigráficas, especialmente em subsuperfície, quando se leva em conta que a mesma seção estratigráfica é referida nos poços ora como Formaçóes Serra Alta e Teresina, ora como Formação Corumbataí. Também causa problemas no posicionamento do conteúdo fossilífero dessas unidades.

Um dos principais resultados deste trabalho é reafirmar que a Formação Serra Alta pode ser reconhecida a norte do Domo de Gibóia, onde apresenta características peculiares. Tais peculiaridades, descritas neste trabalho, representam contribuição para o entendimento da evoluçáo estratigráfica após a implantação do sistema carbonático-evaporítico materializado pela Formação Irati. Desta forma, em se subtraindo da Formaçáo Corumbataí (seçáo correspondente à Formação Serra Alta), a Formação Corumbataí corresponde unicamente à Formaçáo Teresina, como denominação lateral do mesmo intervalo litoestratigráfico, sendo, nessa acepção, considerada neste trabalho.

Assim colocado, no centro-leste do Estado de Sáo Paulo, verificou-se que os estratos da Formação Serra Alta sobrepóem a seção de dolomitos e folhelhos pretos da Formação Irati em contato erosivo (Fig. 8), caracterizando desconformidade estratigráfica reconhecida pelas seguintes evidências: - presença de superfície caracterizada por suave entalhe erosivo nas camadas subjacentes da Formação Irati (Fig. 8; Riccomini 1995);
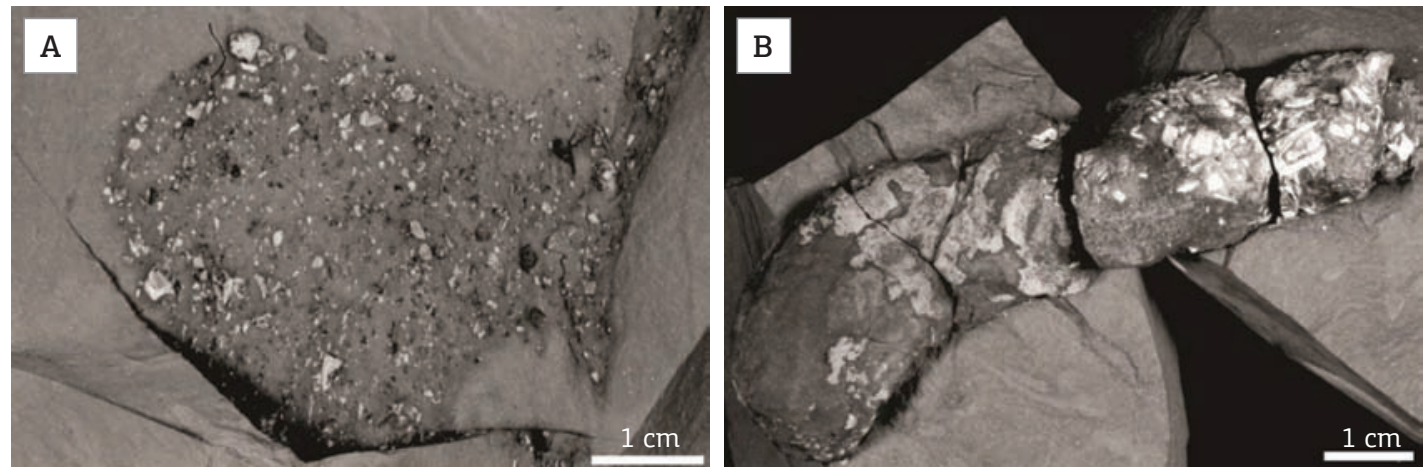

Figura 6. Fósseis característicos da Formação Serra Alta. (A) Detalhe em planta da fácies C em que pode ser observada grande quantidade de bioclastos constituídos por fragmentos ósseos, escamas, dentes e coprólitos de peixes. (B) Coprólito de grande dimensão constituído por uma massa de fragmentos fosfatizados de restos fósseis de peixes. 

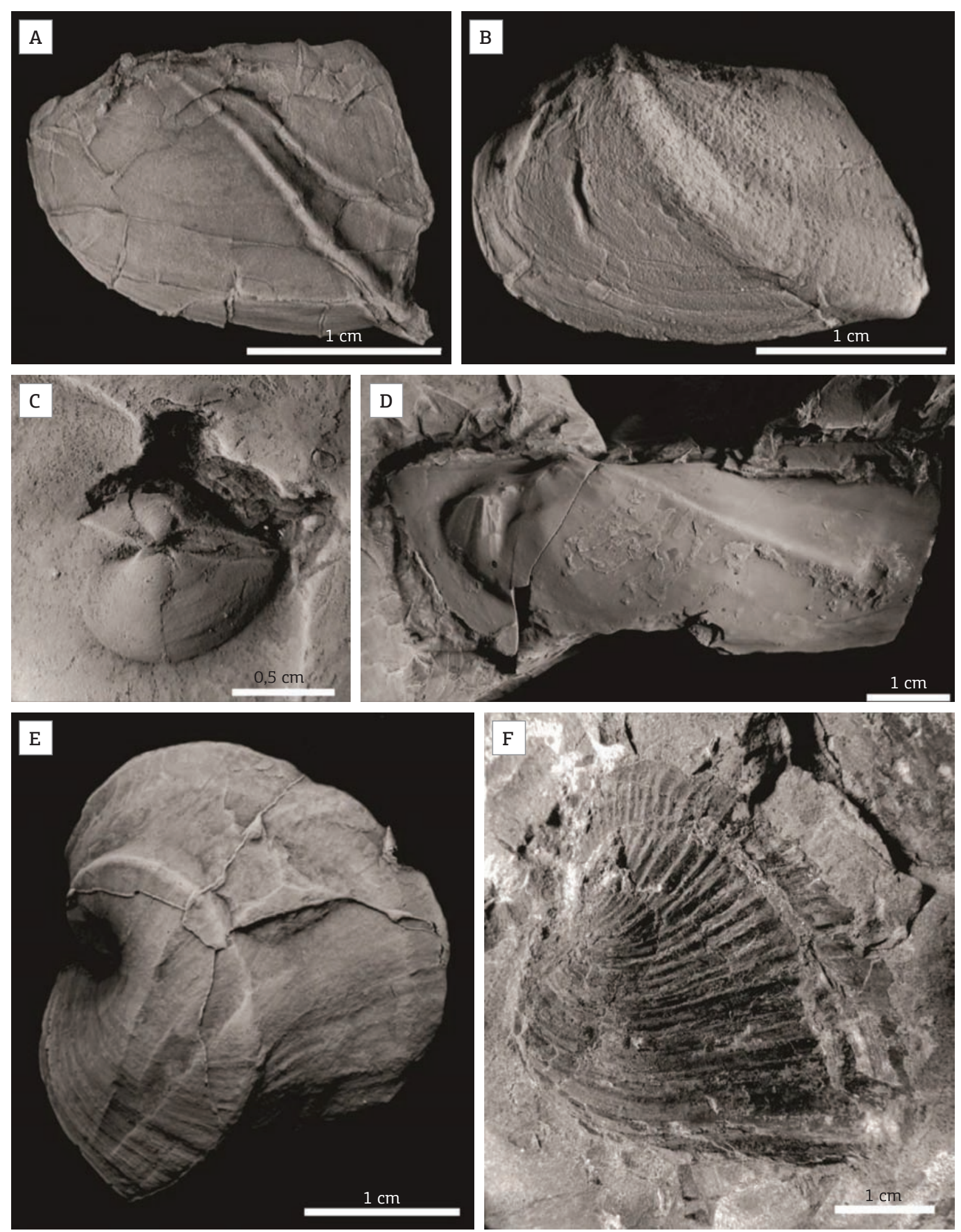

Figura 7. Moluscos bivalves característicos da Formação Serra Alta. (A) Barbosaia angulata, Pedreira Partecal, Rio Claro (SP), DZP-1862; (B) Maackia contorta, Pedreira Partecal, Rio claro, DZP-2375; (C) Rioclaroa levefrei, Rodovia Presidente Castelo Branco, SP-280, Porangaba (SP), DZP-2280; (D) Anhembia froesi, Rodovia Presidente Castelo Branco, SP-280, Porangaba, DZP-2889; (E) Ferrazia simplicicarinata, Rodovia Presidente Castelo Branco, SP-280, Porangaba, DZP-17022; (F) Tambaquyra camargoi, Rodovia Presidente Castelo Branco, SP-280, Porangaba, DZP-2896. 
- mudança drástica de fácies predominantemente carbonáticas da Formação Irati para depósitos arenosos da base da Formação Serra Alta;

- presença de restos retrabalhados de mesossaurídeos nas camadas arenosas basais;

- mudança na tendência de elevação do nível de base da bacia evidenciada pela associação de fácies inferior da Formação Serra Alta.

Depósitos residuais (lags), constituídos por restos de peixes, coprólitos e nódulos fosfáticos, pavimentam superfícies transgressivas que lateralmente se estendem por centenas de metros sobre a descontinuidade basal. Esses lags são formados por joeiramento, durante ciclos de subida do nível relativo do mar (como anteriormente sugerido por Lages 2004 e Holz et al. 2010), materializando incursões marinhas de alta frequência sobre a paleosuperfície da Formação Irati anteriormente exposta. Os depósitos de caráter transgressivo representam a base de uma nova sucessão com características também transgressivas sobre a desconformidade basal (Menezes 1994; Holz et al. 2010). Como esse nível arenoso inferior pôde ser identificado em diversas localidades, propóe-se que represente uma camada de correlaçáo estratigráfica característica da porção inferior da unidade.

Sob a ótica da estratigrafia de sequências, como não há trato de mar baixo, a superfície transgressiva presente na base da Formação Serra Alta coincide com a desconformidade da base da nova sequência deposicional. A identificação do trato de sistema de mar baixo em sinéclises é problemática devido à dificuldade na identificação de discordâncias regionais e no reconhecimento de feições de ravinamento, vales incisos, depósitos costeiros ou de estuários (Witzke et al. 1996). Na sucessão permiana da Bacia do Paraná, essa particularidade ocorre devido às baixas taxas de sedimentação, bem como à falta de padrốes geométricos resultantes da sedimentação na ausência de talude. Sendo assim, os depósitos de tratos de mar baixo estão comumente ausentes ou ocorrem deslocados mergulho abaixo para porçôes interiores da bacia.

Muitas sequências intracratônicas são constituídas pelos tratos transgressivo e de mar alto dispostos em sucessóes com amplas superfícies de inundação e arquitetura caracterizada pela presença de ciclos transgressivo-regressivos de terceira ou quarta ordem (Witzke et al. 1996). Isso se materializa em superfícies de discordâncias amalgamadas com superfícies transgressivas da base do trato transgressivo. Desta forma, as camadas arenosas da associação de fácies da porção inferior da Formação Serra Alta podem ser consideradas como representativas de deposição em condiçóes de trato de sistema transgressivo, com superfícies transgressivas pavimentadas por lags sobre a desconformidade com a Formação Irati (Fig. 4).

A sobreposição das fácies retrabalhadas por ondas por pelitos laminados sugere deposição em condiçóes progressivamente mais distais e profundas. A predominância de depósitos formados por decantação, sem bioturbação e com pouca influência de fluxos trativos, caracteriza essa sucessão como de caráter essencialmente transgressivo, depositada em condiçóes de disoxia a anoxia quase completa. Nesse contexto, a deposição e preservação de restos de peixes, coprólitos e, ocasionalmente, fragmentos vegetais são facilitadas devido à ausência de oxigênio e retrabalhamento.

O empilhamento é transgressivo até a superfície de inundação máxima (SIM) na Formação Serra Alta, posicionada onde os pelitos atingem valores máximos de argilosidade na associação de fácies intermediária. No registro de poços, a SIM encontra-se localizada nos pontos de inflexão da curva do perfil de raios gama, ou seja, nos valores de gama mais elevados, normalmente situados entre 15 e $25 \mathrm{~m}$ acima do contato subjacente com a Formaçáo Irati (Fig. 4). Esse pico de radioatividade nos perfis de raios gama é produto de maior concentração de matéria orgânica preservada e provável presença de compostos de urânio associados.

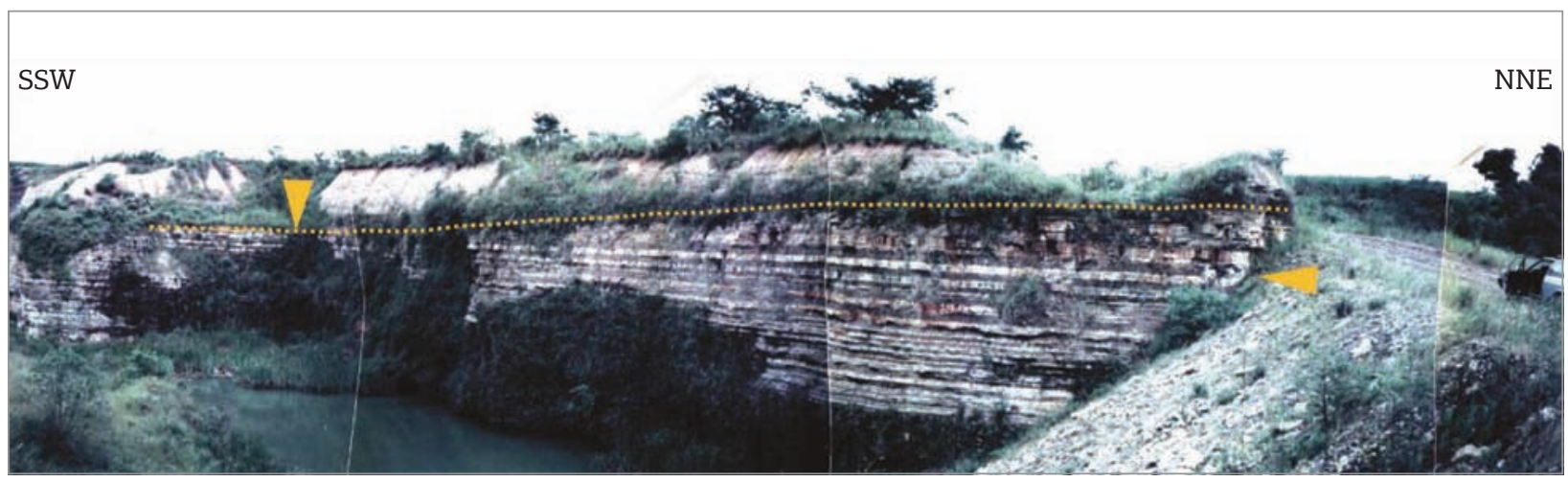

Figura 8. Diastema (desconformidade) entre as Formações Irati e Serra Alta em pedreira atualmente abandonada a norte da cidade de Ipeúna (SP). 
A presença de camadas heterolíticas e de arenitos finos na porção superior da Formação Serra Alta indica retorno de condiçôes proximais de sedimentação. A mudança na coloração dos depósitos pelíticos, de cinza para vermelha, também indica deposição em condições progressivamente mais rasas e oxidantes. Como essa associação ocorre sobre a SIM (Fig. 4) e é patente seu padrão vertical de granocrescência ascendente, interpreta-se que a porção superior regressiva da unidade corresponde a um trato de sistemas de mar alto. O contato com a Formação Corumbataí é marcado pelo aparecimento de camadas decimétricas de arenitos (Fig. 3).

As principais características da Formaçáo Serra Alta que permitem sua distinção da Formação Corumbataí são:

- presença de lags transgressivos na base;

- ausência de camadas carbonáticas significativas;

- presença de restos de fósseis de mesossaurídeos nas camadas arenosas basais;

- predominância de pelitos cinza a pretos, em contraposiçáo às fácies de pelitos avermelhados da Formaçáo Corumbataí;

- pouca bioturbação;

- presença significativamente menor de diques clásticos em comparação com a Formação Corumbataí;

ausência de coquinas centimétricas de conchas de moluscos, uma vez que as conchas de bivalves estáo normalmente dispersas, podendo formar pavimentos (2D), mas nunca depósitos bioclásticos densos (3D); e

- as espécies de bivalves típicas da Formação Serra Alta são Maackia contorta, Barbosaia angulata, Anhembia froesi, Tambaquyra camargoi, Rioclaroa lefevrei e Ferrazia simplicicarinata (Figs. 7A-7F).

A presença de estromatólitos na Formação Teresina evidencia precipitação/bioindução de carbonatos em ambiente evaporítico e reforça a condição de aridez vigente na Bacia do Paraná ao final do período Permiano (Duque 2012). A seção neopermiana mostra tendência regressiva, que culminou na colmatação do corpo d'água (Milani et al. 2007; Warren et al. 2008).

A Formação Serra Alta apresenta diminuição na espessura (Soares \& Landim 1973) e na proporção de folhelhos para oeste no Estado de São Paulo (Fig. 4). As espessuras menores ( $-30 \mathrm{~m})$, verificadas em Limeira, Rio Claro e Piracicaba (Fig. 3), podem estar associadas a uma menor taxa de deposição na área, às variaçóes fisiográficas da bacia ou mesmo à existência de altos estruturais ativos durante a deposição. Nesse sentido, é possível que o Domo de Pitanga já representasse área topograficamente elevada sindeposicional.

De acordo com Simóes et al. (1998), o imenso corpo d'água, em que os sedimentos da Formaçáo Serra Alta foram depositados, seria um "mar epicontinental" que gradualmente teria perdido sua conexão oceânica, tornando-se uma grande bacia endorreica sujeita a altas taxas de evaporaçáo e, portanto, a condiçóes de salinidade variável e alto estresse ambiental (vide também Beurlen 1954; Runnegar \& Newell 1971). Nesse contexto, a deposição da Formação Serra Alta pode ser interpretada como relacionada à inundaçáo final ocorrida nesse imenso corpo d'água (“Golfo Irati” de Milani et al. 2007). A superfície transgressiva contatada na base da unidade e suas características faciológicas reforçam essa hipótese. A sedimentação ocorreu predominantemente em águas com condiçóes de fundo anóxico ou disóxico (Lavina 1991; Rohn 1998; Bondioli 2014).

Do ponto de vista paleontológico, o isolamento da bacia é corroborado pela presença de fauna de bivalves exclusivamente endêmicos na Formação Serra Alta (Runnegar \& Newell 1971; Simóes et al. 1998; Ghilardi \& Simóes 2002). Segundo Simões et al. (2012), exemplares de bivalves fósseis característicos de ambientes dulcícolas coletados na sucessão da Formação Brenton Loch, ilhas Falklands/Malvinas, constituiriam evidência paleoecológica de que as Bacias do Paraná e Karoo já se encontravam isoladas do Oceano Panthalassa durante o Permiano. A ausência de fósseis marinhos (e.g. briozoários e equinodermos) também indica que a bacia não apresentava conexão oceânica e que, portanto, não possuía águas com salinidade normal (Maranhão \& Petri 1996).

A grande distribuição em área e a predominância de fácies de decantação distais em um corpo d'água anóxico sugerem que, durante esse intervalo de tempo, a Bacia do Paraná possivelmente passava por um período de estabilidade tectônica (Meglhioratti 2006). No entanto, evidencias de hidrotermalismo e a presença de estruturas de deformacionais como sismitos e falhas sin-sedimentares nas formaçóes Teresina, Rio do Rasto, Corumbataí e Piramboia indicam que a bacia estava sujeita a esforços tectônicos oriundos das margens de Gondwana (Riccomini et al. 1992; Rostirolla et al. 2000; Yamamoto et al. 2005; Warren 2005). Diques clásticos que seccionam depósitos da Formaçáo Serra Alta nas cercanias das cidades de Piracicaba (SP) confirmam a hipótese de que essa unidade se depositou sob influência de tectonismo ativo (Fig. 9). Os diques arenosos apresentam geometria sinuosa, espessura decimétrica e, localmente, bifurcaçôes para o topo, indicando injeção ascendente a partir de material fluidificado. Nâo raro, cortam mais de uma camada, deformando e deslocando os planos de acamamento (Fig. 9).

A Formação Corumbataí (Pacheco 1927) apresenta composição essencialmente pelítica caracterizada por siltitos e argilitos de coloração cinza que assumem tons rosados em direção ao topo com camadas subordinadas de arenitos e carbonatos.

Dessa maneira, a sucessão de cerca de $50 \mathrm{~m}$ de pelitos cinza anteriormente interpretada como a base da Formação Corumbataí e que ocorre em subsuperfície em quase toda extensão da Bacia do Paraná passa a compor a sucessão sedimentar da Formação Serra Alta. A Formação Corumbataí, 
com espessura estimada em 130 m (Schneider et al. 1974) passa a apresentar espessura média de $90 \mathrm{~m}$. Essa constatação é especialmente válida para as exposições na porção centro-leste do Estado de São Paulo, na qual se encontram as seçôes estratigráficas mais completas da Formação Serra Alta.

\section{CONSIDERAÇÕES FINAIS}

A Formação Serra Alta figura como uma das unidades litoestratigráficas com maior extensão na Bacia do Paraná. Dados paleontológicos e geocronológicos permitem situar a deposição da Formação Serra Alta entre as idades Capitaniana inferior (265 Ma) e Wordiana inferior (268 Ma).

No Estado de São Paulo, a Formação Serra Alta é definida como uma unidade com espessura de no máximo 60 m. A espessura diminui para norte, ocorrendo de forma descontínua na faixa de afloramentos no centro do Estado de São Paulo, onde apresenta características peculiares descritas neste trabalho. É delimitada na base por uma desconformidade erosiva com a Formação Irati. Propôs-se neste trabalho que os pelitos cinza, incluídos na porção inferior da Formação Corumbataí, sejam referidos como Formação
Serra Alta. Propôs-se também que a Formação Corumbataí seja considerada correlata lateral da Formação Teresina a norte do Domo de Gibóia (Munícipio de Rio das Pedras, centro-leste de São Paulo).

No Estado de São Paulo, a Formação Serra Alta é constituída por siltitos laminados e folhelhos pretos, arenitos basais, camadas heterolíticas de topo e abundantes níveis fossilíferos lenticulares constituídos por restos fosfatizados de peixes e coprólitos. Figuram ainda importante fauna de bivalves fósseis endêmicos do Permiano da Bacia do Paraná, fragmentos de gimnospermas, ostracodes e restos fosfatizados de mesossaurídeos na base da unidade.

As distintas fácies sedimentares identificadas em afloramentos existentes no centro-leste do Estado de São Paulo foram agrupadas em três associaçóes:

- Associação inferior, essencialmente arenosa e depositada em condiçóes costeiras abaixo do nível de base das ondas de tempo bom.

- Associação intermediária, pelítica e representativa da deposição em ambiente mais profundo, sob condiçóes de disoxia/anoxia.

- Associação superior, depositada em águas progressivamente mais rasas e oxidantes.

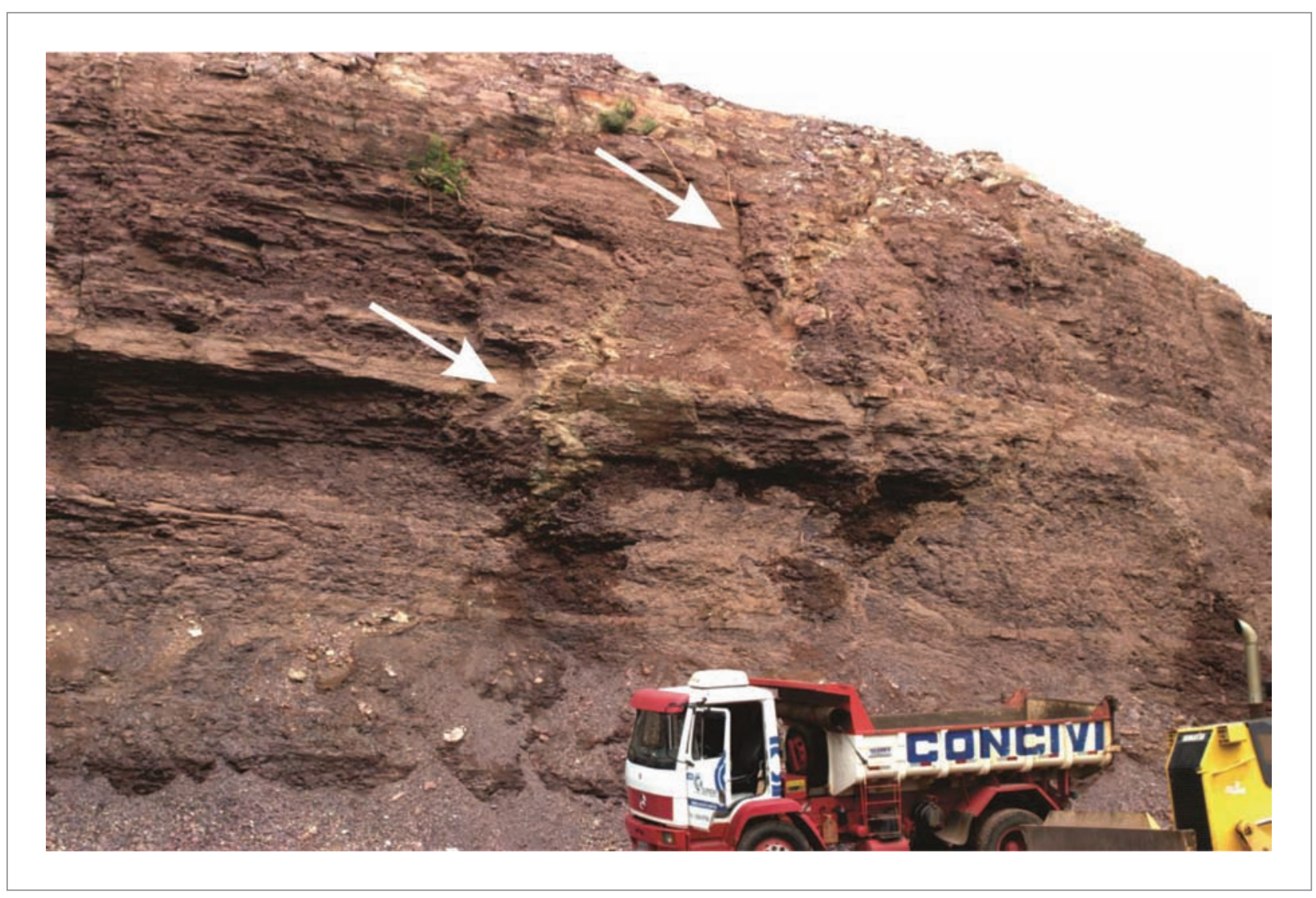

Figura 9. Diques clásticos irregulares seccionando depósitos da associação de fácies intermediária da Formação Serra Alta (setas brancas). A geometria irregular se deve à compactação posterior à colocação do dique. 
O arranjo das associações de fácies evidencia arquitetura estratigráfica inicialmente transgressiva, que se inicia por superfícies transgressivas na base dos depósitos costeiros (amalgamada ao diastema com a Formação Irati) e que evolui para fácies pelíticas depositadas em condição de costa afora, caracterizando trato de sistemas transgressivo. Esse evento transgressivo tem superfície de inundação máxima em folhelhos cinza escuros, reconhecida por pontos de inflexão (maior radioatividade) em perfis de raios gama de poços. A superfície de máxima inundação é reconhecida regionalmente, sendo considerada o último máximo transgressivo no Permiano da Bacia do Paraná (Milani et al. 2007).

A presença de fácies heterolíticas e de camadas arenosas centimétricas na porção superior da Formação Serra Alta e a mudança marcante na coloração dos pelitos, de cinza/pretos para rosa/vermelhos, registram mudança de ambiente redutor para oxidante.

\section{AGRADECIMENTOS}

Os autores externam seus agradecimentos à Fundação de Amparo à Pesquisa do Estado de São Paulo (FAPESP), pelo financiamento deste trabalho (projetos 96/09708-9, 10/19584-4 e 11/20864-4), e à Pedreira Partecal-Partezani, que viabilizou a entrada dos pesquisadores em suas áreas operacionais sempre que solicitado. Agradecem ainda ao revisor (Prof. Dr. Michael Holz, Universidade Federal da Bahia - UFBA) e ao editor (Prof. Dr. Umberto Cordani, Instituto de Geociências da Universidade de São Paulo - IGc/USP), pelas críticas e sugestóes apresentadas, que contribuíram para a melhoria da versão final do artigo. À paleontóloga Suzana Aparecida Matos (pós-graduaçáo, IGc/USP) agradecemos pelas ilustrações dos bivalves fósseis.

\section{REFERÊNCIAS}

Araújo L.M. 2001. Análise da expressão estratigráfica dos parâmetros de geoquímica orgânica e inorgânica nas sequencias Irati. PhD Thesis, Instituto de Geociências, Universidade Federal do Rio Grande do Sul, Porto Alegre, 2v, 301 p.

Barberena M.C., Araujo D.C., Lavina E.L. 1985. Late Permian and Triassic tetrapods of Southern Brazil. National Geographic Research, 1:5-20.

Beurlen K. 1954. Horizontes fossiliferos das Camadas Serra Alta do Paraná. Boletim DNPM, 152:1-30.

Bondioli J.G. 2014. Dinâmica sedimentar, tafonomia e paleoambientes da fácies de offshore da Formação Serra Alta, Permiano, Bacia do Paraná: um estudo de caso no Estado de São Paulo, Brasil. MS Dissertation, Instituto de Geociências, Universidade de São Paulo, São Paulo, 130 p.

Bondioli J.G., Silva S.A.M., Warren L.V., Assine M.L., Riccomini C., Simões M.G. no prelo. The interplay between event and background sedimentation, and the origin of fossil-rich carbonate concretions: a case study in Permian rocks of the Paraná Basin, Brazil. Lethaia.

Brett C.E., Zambito IV J.J., Hundra B.R., Schindler E. 2012a. Mid-Paleozoic trilobite Lagerstätten: models of diagenetically enhanced obrution deposits. Palaios, 27:326-345.

Brett C.E., Zambito IV J.J., Schindler E., Becker T. 2012b. Diagenetically-enhanced trilobite obrution deposits in concretionary limestones: the paradox of "rhythmic events beds". Palaeogeography, Palaeoclimatology, Palaeoecology, 367-368:30-43.

Brito I.M. 1982. Estratigrafia da Bacia do Paraná III: o Grupo Passa Dois. Anais da Academia Brasileira de Ciências, 54(2):460-461.

Castro J.C., Maciel U., Alves C.F.C., Grecchi R.C. 1993. O Grupo Guatá na margem nordeste da Bacia do Paraná: uma revisão. In: I Simpósio sobre a cronoestratigrafia da Bacia do Paraná, Rio Claro. Boletim de Geociências, p. 55-56.

Clifton H.E. 2006. A reexamination of facies models for clastic shorelines. In: Posamentier H.W. \& Walker R.G. (eds.). Facies models revisited. Tulsa, OK, Society for Sedimentary Geology, p. 293-338.
CPRM - Serviço Geológico do Brasil. 1999. Programa Levantamentos Geológicos Básicos do Brasil: Folha Campinas SF-23-YA, impresso, escala 1:250.000. Brasília, CPRM

CPRM - Serviço Geológico do Brasil. 2006. Mapa Geológico do Estado de São Paulo. SIG Brasil, CD-ROM, escala 1:750.000. Brasília, CPRM.

Daemon R.F. \& Quadros L.P. 1970. Bioestratigrafia do Neopaleozóico da Bacia do Paraná. In: 24 Congresso Brasileiro de Geologia, Brasília. Anais, p. 359-412.

Duque J.M. 2012. Fácies carbonáticas da Formação Teresina na borda centro-leste da Bacia do Paraná. MS Dissertation, Instituto de Geociências, Universidade de São Paulo, São Paulo, 69 p.

Gama Junior E. 1979. A sedimentação do Grupo Passa Dois (exclusive Formação Irati): um modelo geomórfico. Revista Brasileira de Geociências, 9(1):1-16.

Ghilardi R.P. \& Simões m.G. 2002. Foram os bivalves do Grupo Passa Dois (exclusive Formação Rio do Rasto), Neopermiano, invertebrados tipicamente dulcícolas? Pesquisas em Geociências, 29(1):3-13.

Gordon Junior m. 1947. Classificação das formações gondwânicas do Paraná, Santa Catarina e Rio Grande do Sul. Notas Preliminares e Estudos, DNPM/DGM, 38:1-20.

Hachiro J. 1996. O Subgrupo Irati (Neopermiano) da Bacia do Paraná PhD Thesis, Instituto de Geociências, Universidade de São Paulo, São Paulo, 196p.

Holz m., França A.B., Souza P.A., Iannuzzi R., Rohn R. 2010. A stratigraphic chart of the Late Carboniferous/Permian succession of the eastern border of the Paraná Basin, Brazil, South America. Journal of South American Earth Sciences, 29:381-399.

Holzfoerster F. 2002. Sedimentology, stratigraphy and synsedimentary tectonics of the Karoo Supergroup in the Huab and Waterberg-Erongo areas, N-Namibia. Beringeria, 30:1-144.

IPT - Instituto de Pesquisas Tecnológicas. 1981. Carta Geológica do Estado de São Paulo, escala 1: 500.000. São Paulo, IPT 
Lages L.C. 2004. A Formação Irati (Grupo Passa Dois, Permiano, Bacia do Paraná) no furo de sondagem FP-01-PR (Sapopema, PR). MS Dissertation, Instituto de Geociências e Ciências Exatas, Universidade Estadual Paulista "Júlio de Mesquita Filho", Rio Claro, 117 p.

Lambert A.M., Kelts K.R., Marshall N.F. 1976. Measurements of density underflows from Walensee, Switzerland. Sedimentology, 23:87-105

Lavina E.L. 1991. Geologia sedimentar e paleogeografia do Neopermiano e Eotriássico (intervalo Kazaniano - Citiano) da Bacia do Paraná. PhD Thesis, Instituto de Geociências, Universidade Federal do Rio Grande do Sul, Porto Alegre, 332 p.

Loczy L. 1966. Evolução paleogeográfica e geotectônica da Bacia Gonduânica do Paraná e do seu embasamento. Boletim da Divisão de Geologia e Mineralogia, 234:1-71.

López-Gamundí O. 2006. Permian plate margin volcanism and tuffs in adjacent basins of west Gondwana: age constraints and common characteristics. Journal of South American Earth Sciences, 22:227-238.

Maack R. 1947. Breves notícias sobre a geologia dos estados do Paraná e Santa Catarina. Arquivos de Biologia e Tecnologia (IBPT), 11:63-154

Maranhão M.S.A.S. 1986. Contribuição ao conhecimento da malacofauna das camadas basais da Formação Corumbataí (Permiano), Estado de São Paulo. MS Dissertation, Instituto de Geociências, Universidade de São Paulo, São Paulo, 88 p.

Maranhão M.S.A.S \& Petri S. 1996. Novas ocorrências de fósseis nas formações Corumbataí e Estrada Nova do Estado de São Paulo e considerações preliminares sobre seus significados paleontológicos e bioestratigráficos. Revista do Instituto Geológico, 17(1-2):33-54

Marques-Toigo M. 1988. Palinologia, bioestratigrafia e paleoecologia do Neopaleozóico da Bacia do Paraná nos Estados do R.G. Sul e Santa Catarina. Brasil. PhD Thesis, Instituto de Geociências, Universidade Federal do Rio Grande do Sul, Porto Alegre, 259 p.

Meglhioratti T. 2006. Estratigrafia de seqüências das formações Serra Alta, Teresina e Rio do Rasto (Permiano da Bacia do Paraná) na porção nordeste do Paraná e centro-sul de São Paulo. MS Dissertation, Instituto de Geociências e Ciências Exatas, Universidade Estadual Paulista “Júlio de Mesquita Filho”, Rio Claro, 129 p.

Mendes J.C. 1952. A Formação Corumbataí na região do Rio Corumbataí (estratigrafia e descrição dos lamelibrânquios). Boletim da Faculdade de Filosofia. Ciências e Letras da Universidade de São Paulo (Série Geologia), 145(8):1-119.

Mendes J.C. 1967. The Passa Dois Group. In: Bigarella J.J., Becker R.D., Pinto I.D. (eds.). Problems in Brazilian Gondwana geology, Curitiba, Instituto de Geologia, p. 119-166.

Mendes J.C. 1984. Sobre os paleoambientes deposicionais do Grupo Passa Dois. Revista do Instituto Geológico, 5(1-2):15-24.

Menezes J.R.C. 1994. Estratigrafia de seqüências em dados de sondagem: aplicação ao Permiano da Bacia do Paraná na região de Candiota (RS). MS Dissertation, Instituto de Geociências, Universidade Federal do Rio Grande do Sul, Porto Alegre, 124 p.

Merlotti S. 2000. Os lenhos fósseis das Formações Irati e Serra Alta (Permiano Superior, Bacia do Paraná) do Rio Grande do Sul, Brasil Registro de Dois Novos Espécimes. Revista Universidade Guarulhos/ Geociências, 5:37-39.

Mezzalira S. 1966. Os fósseis do Estado de São Paulo. Boletim do Instituto Geográfico e Geológico, v. 45. São Paulo, Instituto Geográfico e Geológico, 132 p.

Mezzalira S. 1971. Contribuição ao conhecimento da geologia de subsuperfície e da paleontologia da Formação Irati, no Estado de São Paulo. Anais da Academia Brasileira de Ciências (Suplemento), 43:273-336.
Milani E.J, Melo J.H.G., Souza P.A., Fernandes L.A., França A.B. 2007. Bacia do Paraná. Boletim de Geociências da Petrobras, 15(2):265-287.

Milani E.J. \& Ramos V.A. 1998. Orogenias Paleozoicas no domínio sul-ocidental do Gondwana e os ciclos de subsidência da Bacia do Paraná. Revista Brasileira de Geociências, 28(4):473-484

Moraes Rego L.F. 1930. A geologia do petróleo no Estado de São Paulo. Boletim do Serviço Geológico e Mineral Brasileiro, Rio de Janeiro, $110 \mathrm{p}$

Pacheco J.A. 1927. Relatório elucidativo do esboço geológico da região compreendida entre o meridiano 4 Rio Itararé e os paralelos 2334 e 24 38. Comissão Geográfica e Geológica - exploração da região compreendida pelas folhas topográficas de Sorocaba, Itapetininga, Bury, Sete Barras, Capão Bonito, Ribeirão Branco e Itararé, São Paulo, 9-12 p.

Riccomini C. 1995. Tectonismo gerador e deformador dos depósitos sedimentares Pós-Gondvânicos da porção centro-oriental do Estado de São Paulo e áreas vizinhas. Tese de Livre Docência. Instituto de Geociências, Universidade de São Paulo, São Paulo, 100 p.

Riccomini C., Chamani M.A.C., Agena S.S., Fambrini G.L., Fairchild T.R., Coimbra A.M. 1992. Earthquake-induced liquefaction features in the Corumbataí Formation (Permian, Paraná Basin, Brazil) and the dynamics of Gondwana. Anais da Academia Brasileira de Ciências, $64(3) \cdot 210$

Rocha-Campos A.C., Basei M.A., Nutman A.P., Kleiman L.E., Varela R., Llambias E., Canile F.M., Rosa O.C.R. 2011. 30 million years of Permian volcanism recorded in the Choiyoi igneous province (W Argentina) and their source for younger ash fall deposits in the Paraná Basin: SHRIMP U-Pb zircon geochronology evidence. Gondwana Research, 19:509-523.

Rohn R. 1994. Evolução ambiental da Bacia do Paraná durante o Neopermiano no leste de Santa Catarina e do Paraná. PhD Thesis, Instituto de Geociências, Universidade de São Paulo, São Paulo, $2 \mathrm{v}, 480 \mathrm{p}$.

Rohn R. 1998. O topo da Formação Irati (Bacia do Paraná, Permiano) na região de Rio Claro (SP). In: 40 Congresso Brasileiro de Geologia, Belo Horizonte. Anais, p. 108

Rohn R. 2001. A estratigrafia da Formação Teresina (Permiano, bacia do Paraná) de acordo com furos de sondagem entre Anhembi (SP) e Ortigueira (PR). Correlação de Seqüências Paleozóicas Sul-americanas, 20:209-218.

Rohn R., Lourenço A.T.A., Meglhioratti T. 2003. As formações Serra Alta, Teresina e Rio do Rasto no furo de sondagem SP-23-PR (Permiano, Grupo Passa Dois, Borda Leste da Bacia do Paraná). In: $2^{\circ}$ Congresso Brasileiro de Pesquisa \& Desenvolvimento em Petróleo e Gás, Universidade Federal do Rio de Janeiro, Rio de Janeiro. Resumos, p. 40.

Rostirolla S.P., Assine M.L., Fernandes L.A., Artur P.C. 2000. Reativação de Paleolineamentos durante a evolução da Bacia do Paraná - o exemplo do Domo de Quatiguá. Revista Brasileira de Geociências, 30(4):639-648

Runnegar B. \& Newell N.D. 1971. Caspian-like relict molluscan fauna in South American Permian. Bulletin of the American Museum of Natural History, 146:1-66

Sanford R.M. \& Lange F.W. 1960. Basin-study approach to oil evaluation of Paraná miogeosyncline, south Brazil. AAPG Buletin. 44:1316-1370

Santos R.V., Souza P.A., Alvarenga C.J.S., Dantas E.L., Pimentel M.M. Oliveira C.G., Araujo L.M. 2006. Shrimp U-Pb zircon dating and palinology of bentonitic layers from the Permian Iratí Formation, Paraná Basin, Brazil. Gondwana Research, 9:456-463.

Schneider R.L., Mühlmann H., Tommasi E., Medeiros R.A., Daemon R.F., Nogueira A.A. 1974. Revisão estratigráfica da Bacia do Paraná. In $28^{\circ}$ Congresso Brasileiro de Geologia, Porto Alegre. Anais, v. 1, p. 41-65. 
Simões M.G. \& Fittipaldi F.C. 1987. Bivalves do Grupo Passa Dois, Permiano da Bacia do Paraná: sinopse das pesquisas. In: VI Simpósio Regional de Geologia, Rio Claro. Atas, v. 1, p. 281-295.

Simões M.G., Rocha-Campos A.C., Anelli L.E. 1998. Paleoecology and evolution of Permian bivalve faunas (Paraná Basin) in Brazil. In: Johnston P.A. \& Haggart J.W. (eds.). Bivalves: an Eon of evolution paleobiological studies honoring Norman D. Newell. University of Calgary Press, Calgary, p. 443-452.

Simões M.G. \& Rohn R. 1996. On the significance of a phosphatic concentration at Serra Alta Formation (Passa Dois Group, Late Permian), Paraná Basin, Brazil. In: $39^{\circ}$ Congresso Brasileiro de Geologia, Salvador. Anais, p. 295-297.

Simões M.G., Quaglio F., Warren L.V., Anelli L.E., Stone P., Riccomini C., Grohmann C.H., Chamani M.A.C. 2012. Permian non-marine bivalves of the Falkland Islands and their paleoenvironmental significance. Alcheringa, 36(4):543-554.

Simões M.G. \& Torello F.F. 2003. Modelo de tafofácies para os moluscos bivalves do Grupo Passa Dois (Formações Serra Alta, Teresina e Corumbataí), Permiano Superior, Bacia do Paraná, Brasil. Revista Brasileira de Geociências, 33(3):1-10.

Simões M.G., Torello F.F., Mello L.H.C., Ghilardi R.P. 2000. Conteúdo fossilífero de novos afloramentos do Grupo Passa Dois (Neopermiano) nas porções centro-sul e nordeste do Estado de São Paulo: implicações bioestratigráficas e paleoecológicas. Acta Geologica Leopoldensia XXIII, 50:61-90.

Soares P.C. \& Landim P.M.B. 1973. Aspectos regionais da estratigrafia da Bacia do Paraná no seu flanco nordeste. In: $27^{\circ}$ Congresso Brasileiro de Geologia, Aracaju. Anais, v. 1, p. 243-256.

Sousa S.H.M. 1985. Fácies sedimentares das Formações Estrada Nova e Corumbataí no Estado de São Paulo. MS Dissertation,
Instituto de Geociências, Universidade de São Paulo, São Paulo, 142 p.

Vieira A.J. 1973. Geologia do centro e nordeste do Paraná e centro-sul de São Paulo. In: 270 Congresso Brasileiro de Geologia, Aracaju. Anais, v. 3, p. 259-277.

Wanke A. 2000. Karoo-Etendeka unconformites in NW Namibia and their tectonic implications. PhD Thesis, Würzburg University, Würzburg, $116 \mathrm{p}$.

Warren L.V. 2005. Evolução sedimentar da Formação Rio do Rasto (Permo-Triássico da Bacia do Paraná) na porção centro sul do Estado de Santa Catarina, Brasil. MS Dissertation, Instituto de Geociências, Universidade de São Paulo, São Paulo, p. 174.

Warren L.V., Almeida R.P., Hachiro J., Machado R., Roldan L.F., Steiner S.S. Chamani m.A.C. 2008. Evolução sedimentar da Formação Rio do Rasto (Permo-Triássico da Bacia do Paraná) na porção centro sul do estado de Santa Catarina, Brasil. Revista Brasileira de Geociências, 38(2): 213-227.

White I.C. 1908. Relatório sobre as coal measures e rochas associadas ao sul do Brasil. Rio de Janeiro, Comissão das Minas de Carvão de Pedra do Brasil, 300 p.

Witzke B.J., Ludvigson G.A., Day J. 1996. Introduction: Paleozoic applications of sequence stratigraphy. Geological Society of America Special Paper, 306:1-6.

Yamamoto J.K., Fairchild T.R., Boggiani P.C., Montanheiro T.J., Araúlo C.C., Kiyohara P.K., Matos S.L.F., Soares P.C. 2005. A record of Permian subaqueous vent activity in sountheastern Brazil. Nature, 438:205-207.

Arquivo digital disponível on-line no site www.sbgeo.org.br 